\title{
THE BUSINESS TENANCIES (NI) ORDER 1996 - TO AGREE OR NOT TO AGREE?
}

\author{
Rosemary Carson, Partner, Carson McDowell, Solicitors; and \\ Norma Dawson, Professor of Law, Queen's University, Belfast. *
}

In an earlier issue of the Quarterly ${ }^{1}$ we addressed some practical difficulties arising from the Business Tenancies (NI) Order 1996 ('the Order'). Our remarks were prefaced by a brief introduction to the legislation and the principal changes that it made to the law of business tenancies in Northern Ireland. Readers who wish to be reminded of the general background to this topic are referred to those introductory comments, which will not be repeated here. The purpose of this paper is to highlight potential difficulties arising from the service of a tenant's request for a new tenancy under article 7 of the Order.

\section{First steps in the renewal procedure}

As a business tenancy draws to an end, the renewal procedure under the Order can be triggered by the service of one of two notices, either a notice to determine the tenancy served by the landlord on the tenant under article 6 of the Order, or a request for a new tenancy served by the tenant on the landlord under article 7 of the Order. ${ }^{2}$ In a buoyant market, where rents are rising, it is likely that business tenants will wait until the landlord makes the first move under article 6. Under earlier legislation, the Business Tenancies Act (NI) 1964, it was possible for a tenant to gain an advantage by making a preemptive strike in the renewal procedure. If the tenant acted first and made a request for a new tenancy, by a judicious choice of dates of service and commencement for the new term, the tenant might secure several additional months at the old rent. Under the Order, however, the Lands Tribunal has the power either to vary the rent in a continued tenancy or to backdate the commencement date of the new rent, pursuant to articles 11(3) and 18(4) respectively, thus lessening the economic advantage formerly gained by a pre-emptive strike. It may therefore be more likely now than under the previous legislative regime, that the renewal process will be triggered by a notice to determine under article 6 than by the making of a request for a new tenancy under article 7 . Even so, some tenants will choose to act first. The problems considered in this paper arise when that is the case.

In a practical sense, the request for a new tenancy may be the tenant's first bid in a process of negotiation and the tenant is accordingly required to set out proposals for the terms of the new tenancy. Article 7(3) provides that:

A tenant's request for a new tenancy shall not have effect unless it is made by notice in the prescribed form served on the

\footnotetext{
* We are grateful to those members of the legal profession who drew our attention to the problem addressed here.

1 (2002) 53 NILQ 28.

2 The parties must use the forms prescribed under the Business Tenancies (Notices) Regulations (NI) 1997 (S.R. N.I. No. 2), Forms 3 and 4.
} 
landlord and sets out in general terms the tenant's proposals as to-

(a) the property to be comprised in the new tenancy (being either the whole or part of the property comprised in the current tenancy);

(b) the rent to be payable under the new tenancy;

(c) the duration of the new tenancy; and

(d) the other terms of the new tenancy.

Following service of the tenant's request, article 7(6) of the Order requires the landlord to serve a counter-notice as follows:

Within 2 months of the making of a tenant's request for a new tenancy in accordance with this Article, the landlord shall serve notice on the tenant -

(a) that he is willing to grant a new tenancy on the tenant's terms (or on those terms as modified by an agreement reached between the landlord and the tenant); or

(b) that he will oppose a tenancy application by the tenant (and any such notice shall state on which of the grounds mentioned in Article 12 the landlord will oppose the application). ${ }^{3}$

\section{Article 7(6)(a): 'agreement reached'}

The first question that arises under article 7(6), to which the Order itself provides no clear answer, is the meaning of the word 'reached' in paragraph (a). Does it mean an agreement to be reached in the ensuing negotiations, or an agreement already reached between the parties? The answer is relevant in the following scenario.

A landlord receives a request for a new tenancy and is in general terms willing to grant a renewal, but finds the terms proposed by the tenant unacceptable. The two-month period for service of the landlord's counternotice is coming to an end. The parties have not yet reached agreement on the terms of renewal. Can the landlord safely serve a counter-notice under article 7(6)(a), indicating that he is willing to grant a new tenancy on the tenant's terms 'as modified by an agreement reached' between the parties, in the hope that agreement may still be reached after the notice has been served? If 'reached' means 'already reached', the answer is no. If this is the correct interpretation of 'reached', the period for negotiation is unduly restricted to two months from the service of the tenant's request, which arguably runs counter to the policy underlying the Order ${ }^{4}$ and puts

3 Prior to the enactment of the Order, the Law Reform Advisory Committee for Northern Ireland considered whether the landlord's counter-notice should be abolished as a step in the procedure but decided in favour of its retention as an integral part of the process: LRAC Discussion Paper No. 3, A Review of the Law relating to Business Tenancies in Northern Ireland (1992), HMSO, para 4.2.7, LRAC Report No. 1, Business Tenancies (LRAC No. 2, 1994), HMSO, para 4.3.4.

4 LRAC Report No. 1, paras 4.4.5-6, where it is suggested that the legislation should facilitate negotiation. 
considerable pressure on the parties, especially the landlord. The alternative interpretation, that article 7(6)(a) embraces agreements already reached and to be reached, is more consistent with the general scheme of the Order but may give rise to a second difficulty, which we shall now consider.

\section{Article 7(6)(a) - failure to agree}

If we assume that the landlord has served a counter-notice under article $7(6)(a)$, indicating a willingness to renew on terms still to be agreed, and that negotiations subsequently end without agreement on those terms, the question arises, what happens next? Ideally, the matter should be brought before the Lands Tribunal, which has the power to decide the terms of the new tenancy in the absence of agreement between the parties. ${ }^{5}$ The difficulty is that on these facts neither party appears to have any right to make a tenancy application bringing the matter within the Tribunal's jurisdiction. Only landlords who have opposed renewal may make a tenancy application. ${ }^{6}$ In our scenario, the landlord served a counter-notice under article 7(6)(a), expressing willingness to renew on terms to be agreed, and not under article $7(6)$ (b) stating grounds of opposition to renewal. Equally, the tenant is precluded from making a tenancy application as a result of the wording of article 10(3):

Where a tenant has served a notice containing a request for a new tenancy, a tenancy application may be made to the Lands Tribunal at any time between the date of service of a notice served by the landlord under article $7(6)(\mathrm{b})$ and the date specified in the tenant's request for the beginning of the new tenancy.

This is reflected in the Lands Tribunal (Amendment) Rules (NI) $1997^{7}$ which provide as follows:

E2.- (1) A tenancy application may be made by serving on the registrar a written application in Form EA together with the following documents ...

where a tenancy application is an application made by a tenant for an order for the grant of a new tenancy ...

(ii) a copy of the request for a new tenancy served by the tenant under Article 7(3) and, in that case, a copy of the notice served by the landlord under Article 7(6)(b).

The obvious problem is that the landlord in the case under consideration has served a counter-notice under article 7(6)(a), not article 7(6)(b).

It therefore appears that there is no statutory basis upon which the case may be brought before the Lands Tribunal. As a result, the tenancy will end in accordance with article 7(5) of the Order, immediately before the date specified in the tenant's request for the beginning of a new tenancy. If the tenant continues in occupation paying rent, it is arguable that a periodic tenancy will arise subject to the terms of the Order, and that the parties go

5 Arts $16-19$.

6 Art 12(1).

7 S.R.N.I. 1997 No. 73, Schedule. 
back to the beginning of the process. ${ }^{8}$ By a somewhat circuitous route, this loophole could even re-create the rental advantage formerly gained by the pre-emptive strike. This outcome was probably not intended. The Law Reform Advisory Committee Report on Business Tenancies recommended that:

Where a tenant requests a new tenancy either party should be able to apply to the Tribunal at any time between the date of service of the landlord's counter-notice and the date specified in the tenant's request for the beginning of the new tenancy. ${ }^{9}$

Thus, in the main body of its report, the Committee made no distinction between a landlord's counter-notice under article 7(6)(a) or (b). Had that been carried into legislation, a tenant could make a tenancy application when the parties failed to reach agreement (as happened under the 1964 Act, subject to adherence to strict time limits). The draft Order appended to the LRAC Report does, however, make a distinction between counter-notices served under article 7(6)(a) and those served under article 7(6)(b), only permitting a tenancy application by the tenant where the landlord has served the latter type of counter-notice, an approach that has been adopted in the Order as enacted. This position would appear to support the argument that the words 'by an agreement reached' in article 7(6)(a) means an agreement reached before the two-month time limit has expired, since if agreement is reached during this period, the tenant does not need to make a tenancy application as terms will already have been agreed.

\section{Conclusion}

The confusion surrounding the correct interpretation of article 7(6)(a) and the practical outcome of the loophole caused by a combination of articles 7 and 10, is contrary to the Law Reform Advisory Committee Report on Business Tenancies, and unsatisfactory for both landlords and tenants. It could also result in landlords who are willing to renew on terms to be agreed, seeking to avoid the problem by opposing renewal from the outset or alternatively by not responding to a tenant's notice as they are bound to do pursuant to article $7(6)$, thereby delaying the process into the bargain. If the landlord serves no notice within the two-month time limit under article 7(6), in order to gain time for further negotiations which later break down, the landlord might then apply to the Lands Tribunal for leave to serve a notice out of time. The Tribunal has power under article 10(5)(b) to vary the time limit under article 7(6). If the landlord then serves a notice under article 7(6)(b), the tenant would now be able to make a tenancy application under article 10(3). Thus, it is possible, but by no means certain, that a landlord's failure to serve any notice within the time limit in article 7(6) may afford a means of avoiding the problems raised earlier. Where, however, a landlord has proceeded in good faith to serve a notice under article 7(6)(a) and negotiations break down at a later stage, the problems that we have described appear to be inevitable. The matter could be resolved by clarification of the meaning of article

8 See Walji v Mount Cook Land Ltd (2001) 81 P \& CR D24, for a recent example. The case is discussed in R Highmore and G Clutton, "Buying Time to Negotiate" (2002) Sol J 39.

9 Para 4.4.6. 
200 Northern Ireland Legal Quarterly [Vol. 54, No. 2]

7(6)(a), and the deletion of '(b)' after 'Article 7(6)' in article 10(3) of the Order. 